\title{
DETERMINATION OF TIN IN IRONS AND STEELS
}

\author{
By J. A. Scherrer
}

ABSTRACT

Apparently tin is invariably a constituent of irons and steels, usually in amounts ranging from a few thousandths to a few hundredths of 1 per cent. The accurate determination of such small amounts of tin is difficult, and methods that have previously been recommended are unsauisfactory. Practically all of these methods are based on the reduction of tin to the divalent state, followed by oxidation to the quadrivalent state by means of a standard solution of iodine. The chief sources of errors in such methods lie in failure to remove other compounds that are reduced and oxidized, or in incomplete recovery of tin when separations are attempted. As a result of the present study, a method has been developed in which tin is separated from interfering elements, such as chromium, vanadium, and tungsten, by precipitation as sulphide in dilute nitric acid solution, and then separated from elements, such as copper and molybdenum, by precipitation with ammonium hydroxide. These treatments remove the elements that interfere, and the tin is then reduced in a sulphuric-hydrochloric acid solution containing granulated lead, and afterwards oxidized as usual by means of a standard solution of iodine. With proper precautions, results that are accurate to 0.001 per cent can be easily obtained.

\section{CONTENTS}

I. Introduction

II. Experimental.

1. The choice of the method of analysis

2. Preliminary separation of tin

3. Final separation of tin

4. Reduction and titration of tin.

5. Identification of tin.

6. Sensitiveness, accuracy, and precision of the recommended procedures

1. For irons, plain carbon steels, and alloy steels decomposable by nitric acid

(a) Treatment when tungsten is absent.

(b) Treatment when tungsten is present

(c) Precipitation and determination of tin

2. For alloy steels not decomposable by nitric acid.-..-

(a) Treatment in the absence of tungsten or other insoluble matter

(b) Treatment in the presence of tungsten or other insoluble matter

IV. Tin contents of representative materials

\section{INTRODUCTION}

Tin is not a significant constituent of iron ores, and in the past it has seldom been added to ferrous materials as an alloying constituent. It is, nevertheless, probably always present in irons and steels, unless 
virgin materials have been used. Its source in such materials is either directly or indirectly the tin plate which finds its way into remelting scrap. On the other hand, tin is one of the usual impurities in tungsten ores, and in high-speed steels it is introduced in the ferrotungsten or metallic tungsten. Whether some tin is eliminated during the steel refining process or whether all of it remains and is gradually accumulating is apparently not definitely known. As a general rule, the amount of tin does not exceed 0.01 per cent in cast irons, plain carbon steels, and most alloy steels. High-speed tool steels sometimes contain as much as 0.05 per cent.

The effect of small quantities of tin on the properties of iron and steel has not been exhaustively investigated, but the opinion is growing that tin should not be overlooked. For example, W. Keller ${ }^{1}$ has shown that 0.2 to 2.2 per cent of tin has very marked effects on the tensile strength, elongation, rolling properties, and tendency to develop fissures in steel. The effect of tin on the properties of highspeed tool steels has been studied by French and Digges. ${ }^{2}$ It is possible that tin may be involved in peculiarities in the behavior of certain steels. $^{3}$ It may also have some effect in the nitriding process, for it is well known that nitriding can be prevented by applying a coating of tin.

In addition to the consideration that the metallurgist may need to give to the effect of tin on the properties of steel, the analyst should consider the behavior of tin in methods for the determination of other constituents of steel. For example, in certain methods for the determination of aluminum much, if not all, of the tin is reported as aluminum.

While the conditions in which tin may exist in iron or steel are not established with certainty, there is little doubt that it is largely present in solid solution. Intermetallic compounds, such as $\mathrm{Fe}_{3} \mathrm{Sn}$ and $\mathrm{FeSn}_{2}$, are indicated in the iron-tin equilibrium diagram. ${ }^{4}$ There is little possibility that any tin is present as carbide or nitride, or that the oxide or other oxygenated compounds of tin could survive in molten carbon-bearing steel.

\section{EXPERIMENTAL}

\section{THE CHOICE OF THE METHOD OF ANALYSIS}

The chief methods for the determination of the small amounts of tin that are normally present in ferrous materials are: (1) precipitation as the sulphide and ignition to the oxide, and (2) reduction to the bivalent state and subsequent oxidation to the quadrivalent state by means of a standard solution of iodine. In this study the latter method was chosen because it is fully as accurate as the former, and the preliminary separations are less laborious.

To obtain accurate results by the iodometric method it is, of course, necessary (1) that all of the tin be gathered and then reduced to the divalent state before titrating with iodine and (2) that no iodine be consumed by compounds other than those of tin.

1 Stahl u Eisen, vol. 49, pp. 138-140; 1929.

2 H. J. French and T. G. Digges, Effect of Antimony, Arsenic, Copper, and Tin in High-Speed Tool Steels, Trans. Am. Soc. Steel Treat., vol. 13, pp. 919-940; 1928.

3 For example, in a study of "Steel For Casehardening-Normal and Abnormal Steel," S. Epstein and H. S. Rawdon (B. S. Jour. Research, vol. 2, pp. 423-466; 1928), abnormalities were ascribed to the presence of as little as 0.01 per cent of aluminum. If the steels contained tin, more or less of it would have been reported as aluminum after determinations by the method of chemical analysis that was used.

4 Int. Crit. Tables, vol. 2, p. 452; 1927. McGraw-Hill Book Co. (Inc.). 
It might seem, and indeed it has been recommended, that it would suffice to dissolve plain carbon steels in hydrochloric or sulphuric acid under nonoxidizing conditions, and then to titrate with a standard solution of iodine. Such methods yield erratic results. Results for tin in some steels are high because jodine is consumed by gases or other compounds formed from impurities in the steel. With other steels, results are low for reasons that are difficult to ascertain. Typical analyses are shown in Table 1. Somewhat better, though still incorrect and erratic results are obtained if the solution of the iron is boiled with lead, or lead and antimony, as described in the reduction of the purified solution of tin (p. 318). Results obtained by this procedure are shown in Table 2 .

TABLE 1.-The determination of tin by direct titration with iodine following solution of the sample in sulphuric and hydrochloric acids

\begin{tabular}{|c|c|c|c|c|}
\hline \multirow[b]{2}{*}{ Material } & \multicolumn{2}{|c|}{ Tin } & \multicolumn{2}{|c|}{ Error } \\
\hline & Present & Found & By weight & $\begin{array}{l}\text { Percent- } \\
\text { age }\end{array}$ \\
\hline $\begin{array}{l}\text { B. O. H. steel } 1 \text { per cent C. } \\
\text { Ingot iron } \\
\text { A. O. H. steel } 0.2 \text { per cent C } \\
\text { Tin-bearing steel. }\end{array}$ & $\begin{array}{l}g \\
0.0001 \\
.0008 \\
.0012 \\
.0570\end{array}$ & $\begin{array}{l}g \\
0.0044 \\
.0007 \\
.0030 \\
.0410\end{array}$ & \begin{tabular}{r}
$g$ \\
+0.0043 \\
\hdashline .0001 \\
+.0018 \\
-.0160
\end{tabular} & $\begin{array}{r}4,300 \\
13 \\
150 \\
28\end{array}$ \\
\hline
\end{tabular}

TABLE 2.-The determination of tin by direct titration with iodine following solution of the sample in sulphuric and hydrochloride acids and reduction with lead and antimony

\begin{tabular}{|c|c|c|c|c|}
\hline \multirow[b]{2}{*}{ Material } & \multicolumn{2}{|c|}{$\operatorname{Tin}$} & \multicolumn{2}{|c|}{ Error } \\
\hline & Present & Found & By weight & $\begin{array}{l}\text { Percent- } \\
\text { age }\end{array}$ \\
\hline $\begin{array}{l}\text { B. O. H. steel } 1 \text { per cent } \mathrm{C} \\
\text { Ingot iron } \\
\text { A. O. H. steel } 0.2 \text { per cent } \mathrm{C} . \\
\text { Tin-bearing steel }\end{array}$ & $\begin{array}{l}g \\
0.0001 \\
.0008 \\
.0012 \\
.0570\end{array}$ & $\begin{array}{c}g \\
0.0002 \\
.0007 \\
.0003 \\
.0538\end{array}$ & $\begin{array}{r}g \\
+0.0001 \\
-.0001 \\
-.0009 \\
-.0032\end{array}$ & $\begin{array}{c}100 \\
13 \\
75 \\
5.6\end{array}$ \\
\hline
\end{tabular}

Among the substances that consume iodine should be mentioned sulphides and reduced compounds of vanadium, molybdenum, and chromium, all of which are present in steels and in most cast irons. Tungsten also interferes, for during the reduction process it is reduced to a colored compound which obscures the end point in the subsequent titration.

It is therefore evident that separations must be made before tin can be determined by the iodometric method. 
TABLE 3.-The determination of tin by solution of the sample in sulphuric acid and precipitating with hydrogen sulphide

\begin{tabular}{|c|c|c|c|c|}
\hline \multirow[b]{2}{*}{ Material } & \multicolumn{2}{|c|}{ Tin } & \multicolumn{2}{|c|}{ Error } \\
\hline & Present & Found & By weight & $\begin{array}{l}\text { Percent- } \\
\text { age }\end{array}$ \\
\hline 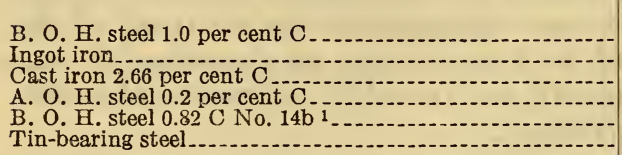 & $\begin{array}{l}0.00010 \\
.0008 \\
.0011 \\
.0012 \\
.0018 \\
.0570\end{array}$ & $\begin{array}{l}. g \\
0.00006 \\
.0007 \\
.0007 \\
.0011 \\
.0006 \\
.0541\end{array}$ & $\begin{array}{l}-0.00004 \\
=.0001 \\
=.0004 \\
=.0001 \\
=.0012 \\
-.0029\end{array}$ & $\begin{array}{r}40 \\
13 \\
36 \\
8 \\
67 \\
5\end{array}$ \\
\hline
\end{tabular}

1 With this steel it was not possible to obtain more than $0.0014 \mathrm{~g}$ of tin by attack with powerful oxidizing agents, such as nitric acid, permanganate, and ammonium persulphate and silver nitrate, following the preliminary solution in sulphuric acid.

\section{PRELIMINARY SEPARATION OF TIN}

The simplest method for separating tin from iron, as well as from elements, such as chromium, vanadium, and tungsten, is by precipitation as the sulphide. In preliminary experiments it was found that complete precipitation of tin could not be obtained when the sample was dissolved in hydrochloric or sulphuric acids. This was at first ascribed to failure to adjust the solution to the proper acidity. Typical results are shown in Table 3. In tests on solutions of pure ferrous and ferric salts to which known amounts of tin and acids had been added it was found, however, that precipitation was complete in solutions that were much more acid than those of the samples of iron. For example, complete precipitation of tin was obtained in $500 \mathrm{ml}$ of solution containing $10 \mathrm{~g}$ of iron as ferrous sulphate, together with as much as $15 \mathrm{ml}$ of sulphuric acid. Further investigation indicated that the incomplete precipitation might be caused by the presence of organic compounds which were derived from the carbides and which formed stable complex ions with the tin. Material containing considerable amounts of carbides or other carbon compounds which are decomposed by dilute nonoxidizing acids, such as hydrochloric or sulphuric, gave more trouble than material containing uncombined carbon, or carbides which are insoluble in these acids. For example, a Bessemer steel containing 0.82 per cent of carbon yielded only about 50 per cent of its tin when dissolved in hydrochloric or sulphuric acid and treated with hydrogen sulphide. On the other hand, a high-speed steel containing 0.66 per cent of carbon, together with tungsten, chromium, and vanadium, which form insoluble carbides, yielded practically all of its tin. The same considerations hold true with cast irons. A cast iron containing 1 per cent of tin, 1.52 per cent of graphite, and 0.72 per cent of combined carbon showed 0.948 per cent of tin when decomposed with sulphuric acid. The complex compound that is formed is so stable that it even resists oxidation by permanganic acid. In view of the uncertainties introduced by the use of hydrochloric or sulphuric acids, it was decided to use the less attractive procedure of dissolving the sample in nitric acid whenever possible. Such an attack permits the complete precipitation of the tin, probably by preventing the formation of objectionable organic compounds. A drawback to the use of nitric acid is that it yields ferric nitrate, which afterwards reacts with hydrogen sulphide and 
liberates considerable sulphur. It was found, however, that the mixture of sulphides and sulphur was not difficult to handle. Nitric acid by itself does not react with hydrogen sulphide if the solution is cold and dilute.

Some steels which do not dissolve in dilute nitric acid dissolve readily if a little hydrofluoric acid is added. So far as the determination of tin is concerned, the use of hydrofluoric acid is not permissible, for precipitation by hydrogen sulphide is incomplete, even though boric acid is added. The use of phosphoric acid in conjunction with sulphuric acid, which might seem attractive for the solution of tungsten-bearing steels, also leads to incomplete precipitation of tin. ${ }^{5}$

Precipitation with hydrogen sulphide can be expected to insure separation of tin from elements such as iron, chromium, vanadium, and tungsten, provided they are in solution at the start. Carbides, tungstides, or other insoluble compounds must be decomposed and dissolved before treatment with hydrogen sulphide is begun. If appreciable amounts of tungsten and vanadium are present tartaric acid is needed to avoid partial precipitation of these elements.

\section{FINAL SEPARATION OF TIN}

Treatment with hydrogen sulphide leaves tin still associated with elements such as copper, molybdenum, antimony, and arsenic. Of these, antimony and arsenic are normally present in only small amount and cause no difficulty in the determination of the small amounts of tin that are involved. The same can be said of selenium or tellurium, should these happen to be present.

Molybdenum interferes and must be removed. Copper is not objectionable unless present in larger amounts than are usually found in steels. Fortunately it is not difficult to separate tin from molybdenum (and also copper), for treatment with an excess of ammonium hydroxide gives a quantitative precipitation of tin with little or no precipitation of molybdenum or copper. In such precipitations it is advantageous to add a little ferric salt to act as a gatherer of the tin and to facilitate the subsequent solution of the precipitate. Incidentally, it should be noted that the precipitate can be expected to contain arsenic and antimony, as well as elements such as tungsten, chromium, and vanadium, if the preliminary treatments have failed to remove them.

\section{REDUCTION AND TITRATION OF TIN}

Various procedures have been recommended for the reduction of tin preliminary to the titration with iodine. In the analysis of bearing metal the author has had excellent results by the use of granulated lead, together with antimony added as the trichloride. This combination is specified in the recommended method as a matter of preference. Antimony can, no doubt, be dispensed with in most analyses. Its use gives rise to more lead chloride than is

\footnotetext{
${ }^{5}$ As regards the behavior of tin when steels are dissolved, it is interesting to note that in experiments with a steel containing 0.57 per cent of tin, the residues showed no tin after attack with dilute hydrochloric a cid (1:3), 0.03 per cent after attack with dilute sulphuric acid (1:5), 0.06 per cent after attack with dilute nitric acid $(1: 4)$, and the full amount $(0.57$ per cont) after solution in iodine as in determinations of slag. All of the tin in the residues could be put in solution by digesting paper and residue in concentrated nitric and sulphuric acids.
} 
obtained by lead alone, and some analysts may prefer to titrate in a clear solution, rather than against the white background of the lead chloride. ${ }^{6}$ The apparatus used in the reduction is shown in Figure 1.

With the small amounts of tin contained in most steels the use of the theoretical titer of the iodine solution leads to no significant error. ${ }^{7}$ If extreme accuracy is required, a more accurate titer can, of course, be obtained by carrying a synthetic sample, composed of pure tin and tin-free iron (or a carefully standardized steel, such as No. $22 \mathrm{~b}$ ) in the proportions present in the sample under test, through all steps of the method. For amounts of tin less than $0.005 \mathrm{~g}$ (10 g samples containing 0.05 per cent of tin) hundredth normal solutions, and for amounts over this, tenth normal solutions are suitable.

\section{IDENTIFICATION OF TIN}

Any determination of tin (particularly very small amounts) by a titration method is open to the question as to whether the standard solution was consumed by tin or by something else. To establish the presence of tin in the Bureau's Standard sample of ingot iron No. 55 , four $50 \mathrm{~g}$ samples were dissolved in dilute sulphuric acid, and the tin, copper, arsenic, antimony, and molybdenum separated as sulphides. The papers and precipitates were combined and dissolved by digestion with nitric and sulphuric acids. Arsenic was removed by distillation, and the copper, antimony, and molybdenum were precipitated in a solution containing oxalic acid, ammonium oxalate and ammonium tartrate in accordance with the Clarke method. The tin was then precipitated by hydrogen sulphide, after the destruction of the oxalic and tartaric acids, and the yellow sulphide tested to confirm the presence of tin. In addition to qualitative verification, the percentage of tin was also determined after this laborious treatment and found to be 0.0067 per cent as compared with 0.0078 per cent obtained by the recommended procedure. The low result was to be expected in view of the incomplete precipitation of tin by hydrogen sulphide in a solution in which the iron was dissolved in sulphuric ácid.

\section{SENSITIVENSS, ACCURACY, AND PRECISION OF THE RECOMMENDED PROCEDURE}

The sensitiveness of the recommended procedure depends (1) on the size of the sample taken, (2) the care with which the end point is obtained, (3) the accuracy to which the volume of the standard solution is read, and (4) the determination of the proper correction. The determination of the latter (iodine needed for impurities in the reagents and for the end point) can be made as usual by carrying the reagents through all steps of the procedure, or by calculating from the volumes of iodine required by samples of different weights, say 5 and $10 \mathrm{~g}$. If small amounts of tin are in question, it is best to use a

6 According to S. G. Clarke (The Analyst, vol, 56, p. 82; 1931, the use of antimony leads to errors (which may be compensating) because some tin is carried down by the reduced antimony and some of the finely divided reduced antimony may react with iodine. That such errors are of no significance in determinations of the small amounts of tin in most steels is demonstrated by the fact that standardizations of a 0.1 $N$ solution of iodine against $100 \mathrm{mg}$ portions of tin which had been reduced by lead in one case and leadantimony chloride in another gave 0.005956 and $0.005966 \mathrm{~g}$ of tin, respectively. For $5 \mathrm{mg}$ portions and a $0.01 \mathrm{~N}$ solution, the titers were 0.000584 and 0.000591 .

7 For example, the tin titer of a $0.1 N$ solution of iodine as found by actual titration against a known amount of tin carried through all steps of the method may be $0.005960 \mathrm{~g}$ of tin as compared with the theoretical titer 0.005935 . 
burette of small bore, say a $10 \mathrm{ml}$ burette graduated to $0.05 \mathrm{ml}$. Such a burette can be read to $0.01 \mathrm{ml}$. Probably the limiting factor in the sensitivity of the method is ability on the part of the analyst to reproduce the end point. With care this need not be in error by more than $0.05 \mathrm{ml}$. Samples can easily be handled in $25 \mathrm{~g}$ units up to the point at which the sulphides have been washed. From this point as many as four papers and residues (representing $100 \mathrm{~g}$ ) can be combined and carried through the rest of the method with little, if any, disturbance of the end point and correction for reagents. The importance of the size of the sample is evident when it is realized that $0.05 \mathrm{ml}$ of $0.01 \mathrm{~N}$ iodine solution (equivalent to $0.00003 \mathrm{~g}$ of tin) represents 0.0003 per cent of tin in a $10 \mathrm{~g}, 0.00012$ per cent in a $25 \mathrm{~g}$ and 0.00006 per cent in a $50 \mathrm{~g}$ sample.

The sensitiveness of the recommended procedure was tested by taking four $25 \mathrm{~g}$ samples of steel, adding $0.00025 \mathrm{~g}$ of tin to each of two samples, and carrying all of the samples through all of the steps of the method. The volumes of $0.01 N$ iodine solution required by the samples to which no tin was added were 0.37 and 0.38 (volume required by the blank and by the tin in the sample), while each of the other samples required $0.81 \mathrm{ml}$. The difference between the volumes required by the treated and untreated samples was, therefore, $0.43 \mathrm{ml}$ which represented $0.000258 \mathrm{~g}$ of tin; or 0.00103 per cent as against the expected 0.001 per cent. In tests on the same steel made at the completion of the work, the volumes of $0.01 \mathrm{~N}$ iodine solution required by 10,25 , and $50 \mathrm{~g}$ samples and by the reagents alone were 0.43 (A), 0.52 (B), 0.70 (C) and 0.37 (D), respectively. $\mathrm{B}-\mathrm{A}, \mathrm{C}-\mathrm{A}$, and $\mathrm{C}-\mathrm{B}$, therefore, represent the corrected volumes of iodine required by 15,40 , and $25 \mathrm{~g}$ samples, respectively, and represent percentages of $0.00036,0.00041$, and 0.00043 , or an average of 0.0004 per cent of tin in the steel. Incidentally, the blank corrections calculated from these titrations are $0.37,0.3 \mathrm{G}, 0.34$, and 0.36 , as compared with 0.37 obtained on the reagents alone.

The probable precision and probable accuracy of the method are illustrated by the data shown in Table 4 .

TABLE 4.-Data illustrating the probable accuracy and the precision of the recommended procedures

[10 g samples]

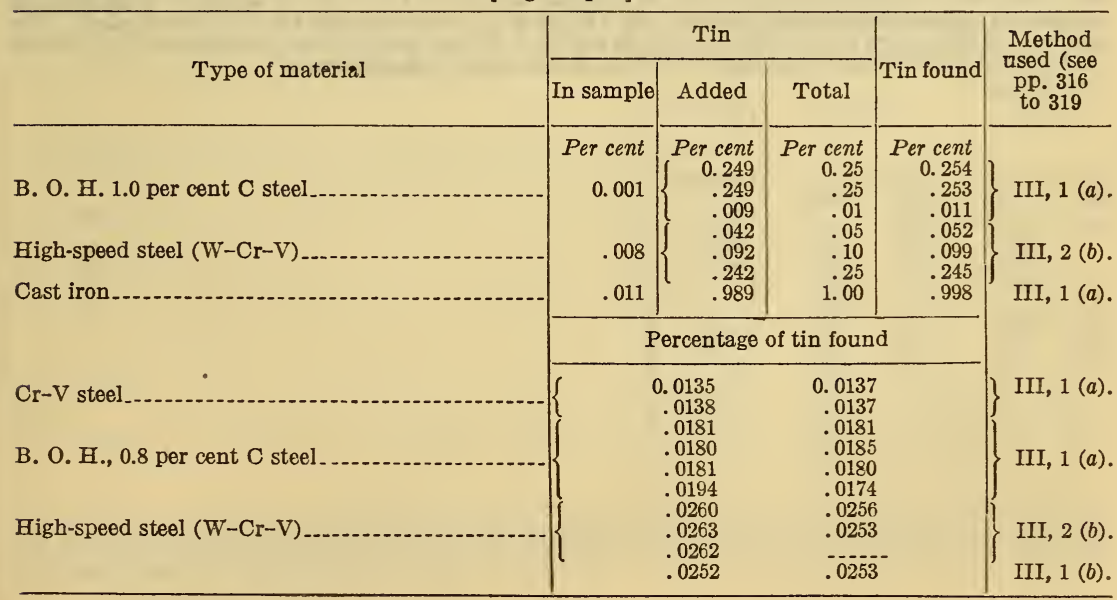




\section{RECOMMENDED PROCEDURES}

\section{FOR IRONS, PLAIN CARBON STEELS, AND ALLOY STEELS DECOMPOSABLE BY NITRIC ACID}

Treat a $10 \mathrm{~g}$ sample of the iron or steel in a $600 \mathrm{ml}$ beaker with 250 $\mathrm{ml}$ of nitric acid $(1: 4)$, cover with a watch glass and warm gently until vigorous action ceases. ${ }^{8}$ Bring nearly to the boiling point, continue heating until the sample is completely decomposed, and then boil for about 5 minutes. Gradually add a saturated solution of potassium permanganate until it is present in slight excess (usually 3 to $5 \mathrm{ml}$ is required), and boil for about 5 minutes. Brown oxides of manganese separate if sufficient permanganate has been added. Cautiously add sulphurous acid until the oxides disappear, and boil for 5 to 10 minutes to expel sulphur dioxide.

\section{(a) TREATMENT WHEN TUNGSTEN IS ABSENT}

If any undecomposed matter remains, filter, wash, and reserve the filtrate. Occasionally the steel leaves a residue which is so finely divided that it passes through the filter. Such steels should be treated as in $(b)$. Transfer the filter paper and residue to a $500 \mathrm{ml}$ Erlenmeyer flask, and add 10 to $12 \mathrm{ml}$ of sulphuric acid (specific gravity 1.84) and about $25 \mathrm{ml}$ of nitric acid (specific gravity 1.42). Heat gently until the first vigorous action is over, then raise the temperature so that the nitric acid is expelled in 30 to 45 minutes and the sulphuric acid is fuming gently. Continue the addition and evaporation of nitric acid in small amounts until the sulphuric acid does not show any evidence of organic matter on fuming. The sulphuric acid should not be too strongly heated, as insoluble chromium sulphate may be formed. Two or three treatments with nitric acid usually suffice. Dilute to about $100 \mathrm{ml}$ with distilled water, add about $10 \mathrm{~g}$ of tartaric acid, and boil until all soluble matter is in solution, and filter if necessary. Neutralize with ammonium hydroxide and add to the reserved filtrate.

\footnotetext{
8 If very small amounts of tin are in question, larger samples and correspondingly larger amounts of reagents can be used. For example, in some tests, $25 \mathrm{~g}$ samples were dissolved in $600 \mathrm{ml}$ of nitric acid (1:4), and the solution diluted to $800 \mathrm{ml}$ before precipitation with hydrogen sulphide. In fact, this modification was used in obtaining the values of steels Nos. $14 \mathrm{~b}, 0.018$ per cent tin; 11d, 0.001 per cent tin; $10 \mathrm{~d}, 0.002$ per cent tin; 23a, 0.0007 per cent tin; and cast irons Nos. $82,0.001$ per cent tin, and $7 \mathrm{~b}, 0.002$ per cent tin. If the material contains an appreciable amount of tin, say over 0.05 per cent, samples smaller than $10 \mathrm{~g}$ can be used. The chief consideration then is to use $22.5 \mathrm{ml}$ of nitric acid (1:4) for each gram of iron in addition to $5 \mathrm{ml}$ for each $100 \mathrm{ml}$ of the solution which is prepared for the hydrogen sulphide treatment.
} 


\section{(b) TREATMENT WHEN TUNGSTEN IS PRESENT ,}

Allow the solution to stand overnight, carefully decant the clear liquid and set it aside. Treat the residue ${ }^{10}$ and small amount of liquid remaining in the beaker with about $20 \mathrm{ml}$ of sulphuric acid and $30 \mathrm{ml}$ of water. Heat just below the boiling point until no more bubbles of gas are given off and then evaporate until the sulphuric acid fumes gently. Add 10 to $15 \mathrm{ml}$ of nitric acid (specific gravity 1.42 ) and again evaporate to slight fumes of sulphuric acid. All black residue should be decomposed. Dilute to about $100 \mathrm{ml}$ with distilled water, add a small excess of ammonium hydroxide and about $10 \mathrm{~g}$ of tartaric acid. When the tartaric acid is in solution again add a slight excess of ammonium hydroxide. The solution should be clear. Make slightly acid and filter off any insoluble matter which may be present. Neutralize and add to the reserved solution.

\section{(c) PRECIPITATION AND DETERMINATION OF TIN}

Cool to room temperature, dilute to about $550 \mathrm{ml}$ or more if desired and treat with a rapid stream of hydrogen sulphide for 30 to 45 minutes. Let settle for 1 to 2 hours, filter and wash with a slightly acid 5 per cent solution of ammonium sulphate which has been saturated with hydrogen sulphide.

Transfer the paper and precipitate to a $500 \mathrm{ml}$ Erlenmeyer flask and decompose with sulphuric and nitric acid as in (a). Fume strongly. Cool and dilute to $100 \mathrm{ml}$ with distilled water.

If the sample contains tungsten, add about $10 \mathrm{~g}$ of tartaric acid. When the acid has dissolved add a slight excess of ammonium hydroxide and heat to boiling. The solution should be clear. Add an excess of about $10 \mathrm{ml}$ of sulphuric acid (specific gravity 1.84), filter, and wash. Dilute the filtrate to about $550 \mathrm{ml}$. Again treat with hydrogen sulphide, filter, wash, dissolve paper, and precipitate and dilute to $100 \mathrm{ml}$ as before.

- This method is recommended for umpire determinations of tin in tungsten steels. Method III, 2 (b) has also given good results with such steels as have been tested, but has the possible weakness that is inber. ent in a sulphuric acid attack. For routine determinations, tungsten steels can be dissolved, and the solution filtered as in method III, $2(b)$. The residue can then be discarded and the filtrate treated as in the method, except that $10 \mathrm{~g}$ of tartaric acid is dissolved, neutralized with ammonia and added to the solution before precipitating with hydrogen sulphide. The following results were obtained by applying the suggested procedures to typical high-speed (W-Cr-V) steels:

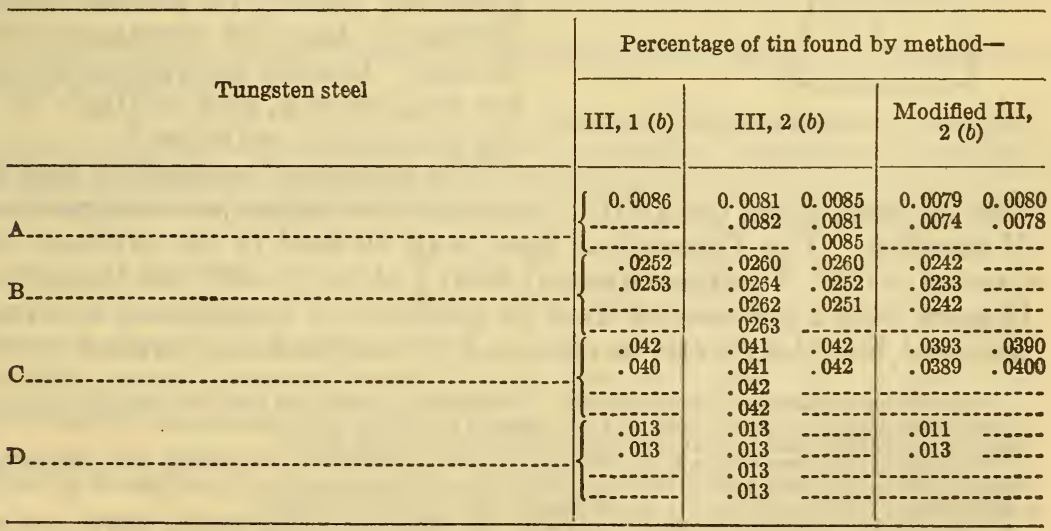

10 The black residue, chiefly carbides of chromium and vanadium, always contains a little tin. For example, in tests of two high-speed tool steels containing 0.026 and 0.042 per cent of tib.t he tin found in the residues represented 0.0011 and 0.0011 per cent. 
Boil until the solution is clear or all soluble matter is in solution. Add $15 \mathrm{mg}$ of hydrochloric acid, and filter to remove sulphur ${ }^{11}$ (also graphite in the case of cast irons) and wash with water.

Add about $40 \mathrm{mg}$ of iron as chloride or sulphate to the filtrate, which should have a volume of about $200 \mathrm{ml}$, heat to boiling and add dilute ammonium hydroxide $(1: 1)$ until in moderate excess (5 to $10 \mathrm{ml}$ ) and boil. Filter and wash three or four times with dilute ammonium hydroxide $(2: 100)$, and two or three times with water. ${ }^{12}$ The filter should not be allowed to run dry, for this causes filtration to become very slow in some cases. Dissolve the precipitate by passing a hot mixture of $80 \mathrm{ml}$ of hydrochloric acid and $100 \mathrm{ml}$ of distilled water

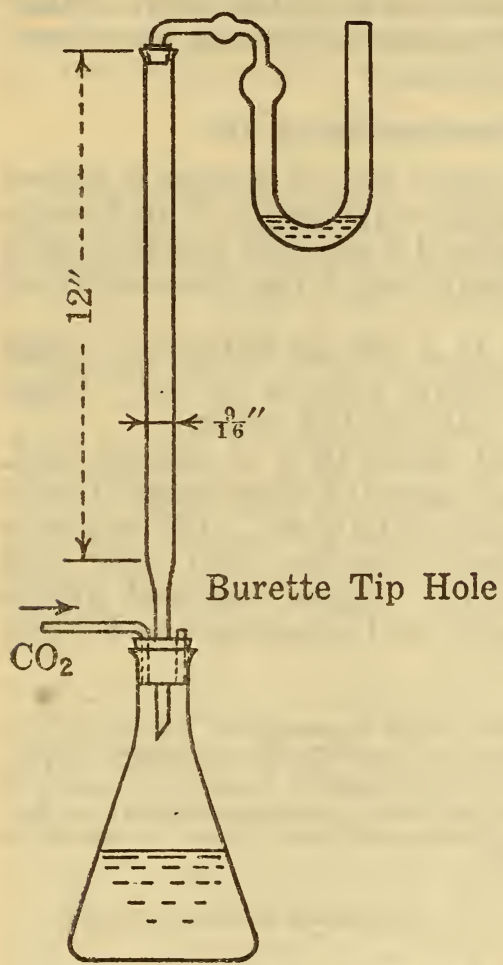

FIgURe 1.-Apparatus for reduction of tin through the paper, catching the solution in a $500 \mathrm{ml}$ Erlenmeyer flask. Dilute to about $350 \mathrm{ml}$, add a solution of about 10 to $15 \mathrm{mg}$ of antimony as chloride or sulphate (see II, 4) and then about $10 \mathrm{~g}$ of test lead. Connect with an air condenser (see fig. 1) and start a stream of carbon dioxide through the apparatus. Heat to boiling and boil gently for 30 to 40 minutes. Cool in a bath of ice water and regulate the current of carbon dioxide so as to prevent back pressure. This may be detected by placing the bubble tube on the end of the air condenser. When the solution has cooled to at least $10^{\circ} \mathrm{C}$., add $5 \mathrm{ml}$ of clear starch solution $(10 \mathrm{~g}$ of soluble starch to 1 liter of water seems to be more sensitive with $0.01 \mathrm{~N}$ iodine solution) through the air condenser. Remove the plug in the third hole of the stopper and immediately insert the tip of the burette $(10 \mathrm{ml}$ capacity in the usual case) containing the standard iodine, or iodate solution. Titrate to the first permanent shade of blue. Deduct the volume required for a blank run, and multiply by the tin titer of the solution. ${ }^{13}$

For material containing less than 0.05 per cent of tin use a $0.01 \mathrm{~N}$ solution; for higher percentages use 0.1 $N$ solution. The theoretical titer may be used in the ordinary case. One $\mathrm{ml}$ of $0.01 \mathrm{~N}$ iodine equals $0.0006 \mathrm{~g}$ of tin (0.0005935 theoretical). If more than 1 per cent of tin is in question, or exceptional accuracy is required, the titer should be obtained by standardizing against pure tin.

11 The sulphur contains very little if any tin. For example, the sulphur residues obtained in the analysis of six 10-gram samples of steels containing an aggregate of $0.0150 \mathrm{~g}$ of tin showed only $0.00012 \mathrm{~g}$ of tin when they were carefully burned and the residues combined and tested for tin.

12 The filtrate contains practically all of the copper and molybdenum. In routine work, the percentage of copper can be estimated from the color of the solution, and the percentage of molybdenum by acidifying, evaporating to a small volume, and proceeding by the colorimetric method.

${ }_{13}$ The addition of potassium iodide is optional. In either case the end point is distinct, and usually requires about $0.37 \mathrm{ml}$ of $0.01 \mathrm{~N}$ solutioni $\mathrm{n}$ the absence of added iodide and about $0.1 \mathrm{ml}$ if $1 \mathrm{~g}$ of iodide has been added. Thei odide can be added with the starch, as, for example, by using 5 ml of a solution prepared as follows: To $500 \mathrm{ml}$ of boiling water add a cold suspension of $5 \mathrm{~g}$ of soluble starch in $25 \mathrm{ml}$ of water. Cool. add a cool solution of $5 \mathrm{~g}$ of sodium hydroxide in $50 \mathrm{ml}$ of water, then add $15 \mathrm{~g}$ of potassium iodide, and mix thoroughly. 


\section{FOR ALLOY STEELS NOT DECOMPOSABLE BY NITRIC ACID}

(a) TREATMENT IN THE ABSENCE OF TUNGSTEN OR OTHER INSOLUBLE MATTER

Treat $10 \mathrm{~g}$ of the sample with $130 \mathrm{ml}$ of sulphuric acid (1:5). Heat on the steam bath until vigorous action ceases. Place on a hot plate, heat gently until decomposition is complete, and then boil for about 5 minutes. Gradually add an excess of crystals of potassium permanganate (5 to $7 \mathrm{~g}$ is usually required) or oxidize with $25 \mathrm{ml}$ of nitric acid $(1: 1)$ and then add an excess of a saturated solution of permanganate. Boil for about 5 minutes. Oxides of manganese should persist. Add 25 to $50 \mathrm{ml}$ of a saturated solution of sulphurous acid, and boil for about 5 to 10 minutes to remove sulphur dioxide. The solution is now ready for treatment with hydrogen sulphide as in III, 1 (c) (p. 317).

(b) TREATMENT IN THE PRESENCE OF TUNGSTEN OR OTHER INSOLUBLE MATTER

Dissolve $10 \mathrm{~g}$ of sample in sulphuric acid, filter, treat the filtrate as in $(a)$ and reserve it. Decompose the paper and residue with nitric and sulphuric acids as in III, $1(b)^{14}$. When tungsten is present the darkening of the residue that takes place on fuming with sulphuric acid should not be mistaken for organic matter. Moreover, the sulphuric acid should be fumed very gently when chromium is present, for strong fuming may yield insoluble compounds of chromium. Dilute to $100 \mathrm{ml}$ with distilled water, heat to boiling, and digest for onehalf to one hour. Add a small excess of ammonium hydroxide and 10 to $15 \mathrm{~g}$ of tartaric acid. When the tartaric acid has dissolved again add a small excess of ammonium hydroxide, and digest on the steam bath until solution is complete or nearly so (usually one-half to one hour). Then add an excess of about $5 \mathrm{ml}$ of sulphuric acid (specific gravity 1.84) and digest on the steam bath for one-half hour. Solution is generally complete at this point. If not, filter, decompose the filter and residue as before, and unite the solution with the other. Neutralize with ammonium hydroxide, add to the reserved filtrate, and treat the combined solutions as in III, 1 (c) (p. 317).

\section{TIN CONTENTS OF REPRESENTATIVE MATERIALS}

The amounts of tin found in representative ferrous materials are shown in Table 5.

14 The residue obtained from tungsten steels always contains a little tin. For example, in a determination in which the main solution and the tungstic acid were treated separately, of a total percentage of 0.026 in the steel, 0.024 was found in the solution and 0.0017 per cent in the tungstic acid. In addition to tin and tungsten, the steel also contained chromium and vanadium. 
TABLE 5.-Tin contents of Bureau of Standards standard samples

\begin{tabular}{|c|c|c|c|}
\hline Material & Tin & Material & Tin \\
\hline 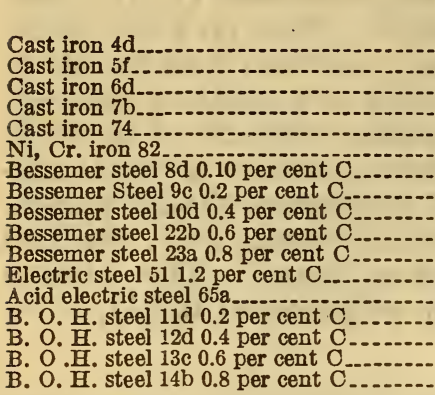 & 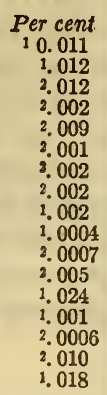 & 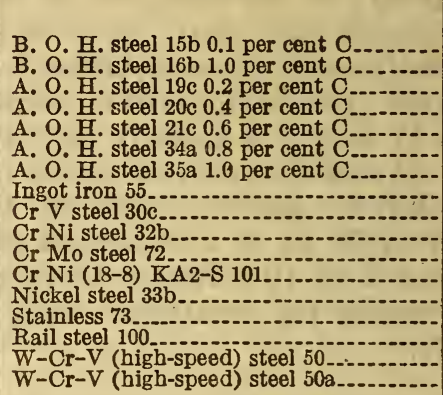 & $\begin{array}{r}\text { Per cent } \\
\text { 20. } 011 \\
\text { 2. } 001 \\
\text { 2. } 012 \\
\text { 2. } 015 \\
\text { 2. } 004 \\
\text { 3. } 007 \\
\text { 3. } 011 \\
\text { 3. } 008 \\
\text { i. } 014 \\
\text { 3. } 013 \\
\text { i. } 009 \\
\text { 3. } 009 \\
\text { 3. } 004 \\
\text { 3. } 007 \\
\text { i. } 008 \\
\text { i. } 026\end{array}$ \\
\hline
\end{tabular}

1 Denotes the average of 3 or more determinations. 2 Denotes 1 determination.

Denotes the average of duplicate determinations.

\section{ACKNOWLEDGMENT}

The author wishes to express his gratitude to Dr. G. E. F. Lundell, of the Bureau of Standards, under whose direction the investigation has been conducted.

Washington, D. C., December 2, 1931. 